\title{
ROCES DEL ALMA CON LA TIERRA. OBJETOS Y SUJETOS FEMENINOS EN LA OBRA DE JOSÉ MARTÍ
}

Mayra Beatriz Martínez Díaz*

RESUMEN: El registro del cuerpo erótico a lo largo de la obra literaria del cubano José Martí se presenta, desde un inicio, como una necesidad ineludible, no relacionada necesariamente con el placer sino, por lo general, con la abstención virtuosa, que resultara inherente a su aspiración personal de constante perfeccionamiento individual, a su empeño de mejoramiento social, y que se conecta con un pensar típicamente androcéntrico. Sin embargo, la elaboración de patrones de conducta en sus textos expresará, al cabo, una lenta, angustiosa, paulatina y desigual evolución de criterios, no sólo determinada, presumiblemente, por sus experiencias directas, sino, en especial, por los afanes subyacentes vinculados con el trazado de papeles genéricos coherentes con los arquetipos que va esbozando para su proyecto de nación. En una misma época, la construcción literaria de sujetos femeninos puede transgredir agresivamente el canon tradicional o afanarse en responder a la normativa más conservadora. ¿Por qué y para qué se producen esas desconcertantes fluctuaciones?

Palabras clave: Martí, Género, Erótica, Modernismo, Androcentrismo, Subalternidad.

No creo aportar alguna novedad al afirmar que José Martí, a más de ciento cincuenta años de su nacimiento, sigue siendo de cierto modo un desconocido. La legenda martiana, es decir "lo que ha de ser leí-

* Centro de Estudios Martianos (maer@cubarte.cult.cu). 
do", ${ }^{1}$ con ser legítima, y no es el caso dudarlo, continúa en gran medida pecando por enaltecimiento sobrado de la espiritualidad normativa —exaltación en cuanto dogma de su pensamiento (alma como psique), y por ello de su trascendencia social— ya sobresaliente de modo natural en la obra del Apóstol, mientras nos priva de esa gustosa empatía que habría de sobrevenir de un discurso que favoreciera la percepción de emociones y acciones vinculadas a su vida íntima, su esfera de acción privada, y que, por analogía con nuestra propia experiencia cotidiana, propiciara la identificación. A la larga, para los estudios y la divulgación martiana se ha convertido lo primero en importante y vigente, en tanto ha sido postergado lo segundo, por ser considerado menos significante y, con ello, no pertinente, en virtud de un funcionalismo típicamente moderno. ${ }^{2}$

${ }^{1}$ Utilizo este término del latín medieval remedando su sentido original, cuando, durante algunos oficios religiosos de la primitiva iglesia cristiana, se leían en voz alta legendas $o$ vidas de santos, tratados hagiográficos en los cuales se producía una exaltación rayana con lo fantástico de aquellos que habían sido virtuosos hasta un grado sobrehumano.

${ }^{2}$ Menciono el funcionalismo en tanto que, como teoría - al modo en que fuera desarrollada por Montesquieu y los ilustrados - sostiene que la sociedad es un organismo donde cada parte cumple una finalidad o realiza una función y todos los miembros de la sociedad han de cooperar para cubrir sus necesidades porque tienen objetivos y valores comunes. Rufo Caballero, en su ensayo "De mis sinuosos amores con el posmodernismo", UNIÓN, núm. 37, La Habana, 1999, pp. 60-63, se ha referido a él, igualmente, como "la más acabada correspondencia respecto de una modernidad pragmática y utopista” (Ibid., p. 62). Este autor también allí discurre esclarecedoramente en torno al proceso de magnificación de los valores espirituales que nos ocupa. Califica como "jaula de hierro de la modernidad" a esa "reificación y absolutización de los valores espirituales y la lógica social, amparada en un estandarte humanista que llegó a encontrar en la dura realidad su negativo fotográfico" (Ibid., p. 62). De igual modo, Emilio Ichikawa ha abordado el afán ordenador moderno que sacrifica la singularidad en pos de un proyecto utópico al que tributa la sociedad toda, y refiere cómo se "concibe su instrumentación en términos de razón práctica": "una moral centrada en lo bueno, un arte bello, una ciencia verdadera, un derecho justo, una técnica eficiente, una política nacional-integradora, una religión ordenadora" (Emilio Ichikawa, "La posmodernidad explicada a mí mismo", en op. cit., p. 57). 
Tal extrema prioridad dada históricamente a su proyección preceptiva, unida al consecuente alejamiento de su proyección perceptiva como individuo, no en su acción social, desarrollada en terrenos de esa "modernidad modélica, idílica, lejana", ${ }^{3}$ ha devenido principal obstáculo para una mayor participación afectiva por parte del receptor en el proceso de comunicación de su legado. Por lo común, se ve a Martí como un ser vehemente, poseso por sus ideas, sobrehumano e inalcanzable: tan extraordinario resulta, que, como paradigma, es menos operante que lo deseado.

Ciertamente, a instancias de esa operación escamoteadora o al menos distanciadora a que aludíamos, la desaparición física martiana ha ido mucho más allá de la muerte misma, de la corrupción de su "substancia", ${ }^{4}$ porque ha entrañado el ocultamiento en gran medida del cuerpo que fue - la incomprensión de su ser material en vida - comportamiento que reproduce, en la lectura de su legado, la arraigada dicotomía cristiana cuerpo corruptible-alma inmortal, vigente de algún modo en el típico patrón de reflexión y comportamiento identitario cubano, que aún hace espacio al pecado a la manera bíblica, en particular respecto a nuestra conducta y prescripciones en esferas tan importantes del desempeño humano como la sexual, y que, desde luego, también fuera motivo de angustia incesante para el Apóstol.

Sabemos, paradójicamente, que el ser singular martiano, su modo peculiar de existencia: necesidades, sentimientos, sensaciones... y sus conflictos en cuanto a la asunción de esa propia dicotomía cuerpo-alma, fue sobradamente expresado por él —en tanto testimonio de su praxis, en tanto proceso indispensable para alcanzar su perfeccionamiento espiritual — como fundamento mismo de su honda eticidad. Martí fue capaz de reconocer precozmente cómo, a un tiempo, era una "personalidad briosa e impotente, libérrima y esclava, nobilísima y miserable, divina

${ }^{3}$ Rufo Caballero, América clásica, La Habana, Ediciones unión, 2000, p. 109.

4 "En el ser humano, el cuerpo es la sustancia”, en José Martí, "Cuadernos de apuntes", núm. 2, en Obras completas, Ciudad de La Habana, Editorial de Ciencias Sociales, 1975 , t. 21 , p. 61. 
y humanísima, delicada y grosera, noche y luz", 5 revelando, además, el advenimiento de una autoconciencia represiva - indispensable al hombre público- que no hará más que traspasar a sus textos.

La tendencia apreciable en los estudios biográficos o en las exégesis de sus textos a lo largo de la modernidad — cualquiera que fuera la posición política y filosófica de sus autores, y tal cual es el caso del culto a las figuras de los santos cristianos virtuosos hasta un extremo heroico- ha sido la de excluir o, en los mejores casos, aligerar la presencia de la contradicción, la ocurrencia del error o la existencia de la inseguridad; la de declarar la preeminencia inalterable de la "pureza", o lo que se entiende por ella, en la visión ofrecida respecto a la reflexión y la acción martiana, suplantando impropiamente el ser martiano por su deber ser, cuyo principal propósito fuera la purificación pitagórica: el perfeccionamiento incansable del alma mediante el cultivo de la virtud.

A la manera de los héroes paganos de la épica grecolatina — quienes no eran individuos, sino arquetipos culturales, cuyas hazañas reales o fantásticas servían para alimentar la autoestima colectiva—, su figura ha sido proyectada como expresión del carácter y los ideales de todo un pueblo. Tributaria de la "leyenda" al fin, en su mayoría esta bibliografía parte de presupuestos reales, pero ellos resultan, inevitablemente, idealizados a partir del siempre gravitante peso de la finalidad. Por lo general, como se conoce, los textos que abordan la vida y la obra del Apóstol poseen un fuerte matiz educativo que se dirige a la reafirmación del discurso de identidad cubano, del cual fueran, sin dudas, asientos esenciales. Martí, supuestamente vulnerable en su papel de hombre, encarnó en paradigma de lo superior, de lo trascendente, de lo que podía proyectarse hacia un futuro utópico y emancipador dentro del mega relato de la historia de Cuba.

Esta operación que, resultado de un pretendido respeto, desde luego, ha escondido buena parte de la "realidad" martiana, llegó a propiciar un

5 Martí, op. cit., p. 68. 
vacío significacional en el territorio donde debían registrarse las mediaciones imprescindibles a la concepción de su ideario maduro, las contradicciones inherentes a todo proceso gestor, esa "nada" correspondería al escenario de sus desasosiegos más íntimos, de sus debilidades, de la complacencia o insatisfacción de sus urgencias cotidianas, de experiencias fallidas o gozosas. Semejante espacio soslayado o escasamente abordado ha devenido, por omisión, en fácilmente reescribible, algunas veces utilizado en contra de la propia leyenda, en momentos como los actuales, cuando existe una urgencia, o a veces rayana en el fanatismo, por inscribir "nuevos" relatos o por insertar en el discurso oficial los hasta entonces relegados. Obviamente, en el caso de la cultura cubana, entre todos los relatos posibles a establecer, desde los márgenes o hasta "oficializar", está lo no dicho por la tradicional "leyenda Martî", lo cual implica, en específico, completar y esclarecer los nexos entre el hombre que fuera: su ser, esfera de acción como individuo concreto, y el proyecto que llegara, según su práctica, a concebir: su deber ser, esfera de mayor repercusión social.

Para acercarlo definitivamente a nosotros y a quienes nos sucederán, el reencauzamiento de la divulgación y los estudios martianos con seguridad debe encaminarse hacia esa personalización —individualización- de Martí-hombre como objeto de investigación, que nos ayude no tanto, como hasta ahora, a describirlo sino a explicarlo: a recuperar al individuo real tras el proyecto cultural. ${ }^{6}$

${ }^{6}$ Rufo Caballero, comentando en torno a esta problemática, coincide con el culturólogo alemán Andreas Huyssen: "[Huyssen] ha llegado a precisar que, lejos del (desuso de la utopía) que preconizara el primer posmodernismo y su extensión transvanguardista, cuanto se requiere hoy, por el contrario, es una reorientación de los ímpetus utópicos del pensamiento: si ayer esa utopía gustaba mirar al futuro como parte de la "proyección óptima" tan de la preferencia de la vanguardia histórica, el nuevo imaginario proyectivo se ocupa más del pasado, en un buceo en la memoria que abjurando del fundamentalismo arqueológico de la modernidad, revisita el legado como forma de recuperar lo real." Caballero, op. cit., p. 109. 
Y "lo real" martiano que nos ocupa subyace, en gran medida, en el cuerpo silenciado.

II

El registro del cuerpo a lo largo de la literatura martiana entraña un sentimiento profundo del conocimiento del sí propio y del hombre en general. Se presenta como una necesidad ineludible que no se relaciona necesariamente con el placer sino, por lo general, con la abstención virtuosa aunque torturante, inherente a su aspiración de constante perfeccionamiento individual y a su empeño de mejoramiento social. ${ }^{7}$ Deseó explícitamente hacer de su vida un constante ejercicio ascético, aceptando como fatal el sufrimiento, la subordinación de la gratificación corpórea a los límites dictados por la razón, y con ello a la justicia, a la belleza, al bien. No obstante, su abnegación y renuncia fueron constantemente conflictivas, tal vez por resultar ajenas a su propia naturaleza y a las contingencias que su circunstancia le deparó. Desconcierto y turbación ante lo inevitable del "envilecimiento" lo acompañaron de por vida, dotando de especial complejidad su reflexión en torno al cuerpo.

Algunos autores han trabajado ya hace algún tiempo la temática de la erótica martiana, ${ }^{8}$ como escenario privilegiado de su discurso del cuerpo, pero, generalmente, los estudios se adscriben en especial al abordaje de los textos poéticos. Sin embargo, creemos que dentro de su obra en prosa, de ficción o testimonial — a pesar de inscribirse en un discurso con mayor vocación ancilar donde la construcción de una propuesta ética constituye uno de los propósitos fundamentales- pueden encontrarse elementos muy significativos unidos a la elaboración de patrones de conducta erótica, que son expresión, en gran medida, de las fluctuaciones que se operan en su concepción de la relación alma-cuerpo. Se

7 "Pasión por el deber: preferencia por el martirio voluntario, esto es alma que asciende. Lo otro es cuerpo que retiene. Esa clase de cuerpo que hay que vencer". José Martí, "Otros fragmentos", núm. 22, en Obras completas, t. 22, p. 322.

${ }^{8}$ Muy en especial Víctor Fowler. 
hace evidente una lenta, pero paulatina evolución de criterios, manifestados a través del deber ser, que una y otra vez apunta y precisa, presumiblemente no determinada por sus experiencias directas, sino por los afanes subyacentes vinculados con el trazado de papeles genéricos coherentes con el arquetipo que va esbozando para su proyecto de nación.

La femineidad en particular, vista como especialización sociocultural y en un inicio circunscrita al ámbito privado, retirado, oculto — procreación y apoyo al hombre: la mujer como vientre, espacio nutricio ajeno al placer-, se abrirá poco a poco a un espacio público donde ella habrá de cumplir nuevas funciones, al tiempo que el cuerpo erótico femenino empieza a hacerse visible, sobre todo en su obra dramática, poética, testimonial y narrativa: la mujer comienza sutilmente a "desnudarse" y, de objeto de placer masculino, cuerpo considerado tabú, pasa a ser, de igual modo, sujeto de placer, cuerpo reconocido.

En el contexto cultural latinoamericano procederes semejantes suelen apreciarse en la narrativa y la poesía modernistas: se conciben a partir de una declaración bastante extendida de oposición al conocimiento metafísico, característico de los patrones escolásticos coloniales de los que formaron parte, desde luego, los presupuestos filosóficos sensualistas y empiristas martianos, provenientes de la tradición del pensamiento filosófico cubano y, por supuesto, de la Ilustración; rechazo que era de primordial importancia en tanto permitía una percepción directa de nuestro entorno físico particular, ayudando a identificarlo y a definirlo con posterioridad. Para muchos escritores de nuestro modernismo, hijos de naciones ya liberadas del dominio español y que comenzaban de algún modo a insertarse — desde los márgenes — en el desarrollo capitalista alcanzado por naciones donde el dogmatismo de la férrea Iglesia católica resultaba inoperante, este proceso no resultó muy difícil.

El erotismo expresado corporalmente, entrevisto en el romanticismo anterior — que adelantaba la celebración rousseauniana de la libertad del espíritu humano que siente "antes de pensar", la exaltación de los sentimientos amorosos hasta el punto de justificar el suicidio por un amor no correspondido, una tendencia acentuada al frenesí, a la melancolía, al 
hastío del mundo y a la autodestrucción-, se magnifica entonces en una fiesta declarada de los sentidos: en un epicureísmo que ha sido considerado marca típicamente modernista, donde el cuerpo femenino como objeto de placer es frecuentación habitual.

Tal explosión literaria de los sentidos se hizo patente en el reflejo que hace la obra martiana de los múltiples planos de la experiencia humana, aunque, mucho más que el resto de sus contemporáneos, mantuvo una fuerte espiritualidad de raíz romántica y una voluntad educativa de hacerla evidente, que lo llevó a operar específicamente en la esfera de lo erótico de forma muy contenida. Así, nos hallamos ante la paradoja de este proceder típico martiano: quien justo pretendía fijar las más audaces prescripciones a través de un proyecto cultural revolucionario en su sentido más amplio, capaz de incluir rupturas y transgresiones radicales en otras esferas, como la política. Establece al mismo tiempo, al menos explícitamente, un discurso erótico que, para la época y en general, puede considerarse conservador.

Creo que, obviamente, para intentar realizar un abordaje menos maniqueo y absoluto de este controvertido tema, habría que desarrollar una reflexión mucho más ambiciosa de la que puedo proponerme en estas líneas. Pero de hacerlo, pienso que debería atender dos vertientes fundamentales: por un lado, tendría que sopesar lo suficiente los presupuestos contextuales y culturales específicos en que nació y se desarrolló la vida y el pensamiento del Apóstol; por otro, habría de intentar establecer en detalle una línea de progresión — presumiblemente matizada por reiteradas intermitencias, según el carácter del documento de que se trate y sus presuntos destinatarios-, que evidentemente existe en el pensamiento martiano referido al amor de pareja y al ideal femenino, cuyos inicios podrían buscarse en la conocida misiva enviada a su madre desde presidio en 1869, y cuya culminación hallaríamos a inicios de la década de los noventa, con sus textos periodísticos, y, ya en 1895 , con sus cartas a María y Carmen Mantilla, a Carmen Miyares y sus últimos diarios de campaña. Me gustaría, no obstante, aventurar apenas algunos elementos de juicio, que considero elocuentes. 
Es un hecho innegable que en la timorata sociedad cubana del siglo XIX - aún colonia de una metrópoli abroquelada en su censura a ultranza de las transformaciones del mundo moderno como las provenientes de la revolución industrial y de las ideas ilustradas que sirvieran de fundamento a la Revolución francesa y a la independencia de las trece colonias norteamericanas $-{ }^{9}$ el discurso literario amatorio se movió siempre de modo bien precario en un controvertido espacio de sombra, dando fe del status represivo que en esta región caracterizaba a la centuria. En narraciones clave de nuestro movimiento romántico — Francisco, de Anselmo Suárez y Romero; $S a b$, de Gertrudis Gómez de Avellaneda; Cecilia Valdés, de Cirilo Villaverde- el goce amoroso sólo logra ser descrito en su dimensión de placer sexual cuando aborda el tema en uniones heterosexuales "prohibidas" — y por lo tanto mayormente ocultas- en las que se evidencia mezcla racial negro-blanco o mestizoblanco, y donde los primeros elementos de las parejas, sean indistintamente hombres o mujeres, bien cargan con la "culpa" del desfogue erótico o resultan, al decir de Víctor Fowler, receptores de "un acto de victimización o uso del dominado como objeto de placer". ${ }^{10}$

En cualquier caso, fueron ésas las escasas relaciones pasionales que pudieron potenciar una "oposición a un orden que se estima debe ser combatido", aunque siempre a través de una "experiencia dolorosa"11 como reflejo directo de lo que ocurría, realmente, en la sociedad de la época. Martí se adscribe, obviamente, a esta línea de la escritura erótica cubana donde lo sexual — y con ello la sensación corpórea— se asienta siempre sobre lo prohibido. La historia de nuestro discurso erótico es la historia de un angustioso combate por la revelación de lo oculto; de una negación permanente que, al cabo, y por oposición, también destaca, señala, descubre.

${ }^{9}$ Pablo Guadarrama, en su libro Humanismo en el pensamiento latinoamericano, aborda exhaustivamente esta aprensión ibérica.

${ }^{10}$ Víctor Fowler, "Estrategias para cuerpos tensos: po(li)(é)ticas del cruce interracial", en Historias del cuerpo, La Habana, Ed. Letras Cubanas, 2001, p. 99. Las cursivas son mías.

${ }^{11}$ Ibid., p. 100. 
Martí responde, en gran medida y por necesidad, a esta moralina de ascendencia hispánica recibida desde la cuna, parte de su espacio sociopsicológico y cultural de pertenencia. La enarbola, incluso, junto a otros territorios de resistencia - la influencia de la tradición literaria del Siglo de Oro español en su obra, es otro ejemplo- como componente del proyecto cultural que pretende estructurar sobre bases auténticas, frente a la irrupción de los modelos culturales exógenos ofrecidos por las nuevas sociedades capitalistas ajenas — europeas en general y estadounidense en específico- que habían logrado penetrar en las nuevas repúblicas hispanoamericanas.

Iván Schulman aborda en sus estudios esta relación directa entre las estrategias martianas de narrar y el proyecto de representar, de "proyectar" la nación, apuntando la evidente crítica que Martí ejerce, desde una posición de reconocimiento a nuestros fundamentos culturales, en torno a la idoneidad del proyecto económico moderno del incipiente capitalismo: "censura sus consecuencias sociales (pensando en el pueblo hispanoamericano) y somete a un examen crítico los valores de la modernidad", adscribiéndose a una visible posición antimoderna. ${ }^{12}$

Resulta curioso, sin embargo, que dentro de la propia cultura española donde Martí bebe, y a pesar de los tradicionales prejuicios religiosos y de que la Inquisición hizo que muchas obras circularan de modo secreto y en forma manuscrita, como algunas de Fernández de Moratín y Samaniego, las manifestaciones de la novela y la poesía eróticas con implicaciones carnales habían sido menos limitadas. Personajes como la Trotaconventos del Libro de Buen Amor, la Alcahueta de La Celestina $y$ el Don Juan de El Burlador de Sevilla constituían prototipos bien asimilados por la cultura ibérica. Publican poesía en torno al tema los más grandes escritores del Siglo de Oro, como Lope de Vega, Quevedo o Góngora. Algunos autores mencionan como elemento explicativo la enorme influencia en la educación del joven Martí de sus lecturas de los

12 Iván A. Schulman, Relecturas martianas: narración y nación, Amsterdam-Atlanta, Ed. Rodolfi, 1994, p. 5. 
místicos españoles. Rafael Rojas, en específico, subraya la "combinatoria entre patrística y estoicismo" que fuera "tan decisiva para la formación de genealogía intelectual cubana". ${ }^{13}$

En carta a su hermana Amelia de 1880, por ejemplo, Martí, ya con veintisiete años, insiste —al menos en el caso de la mujer- en el papel del alma en el logro del amor verdadero: "Una mujer de alma severa e inteligencia justa debe distinguir entre el placer íntimo $y$ vivo, que semeja el amor sin serlo [...] y ese otro amor definitivo y grandioso, como es el apegamiento inefable de un espíritu a otro". ${ }^{14}$ Como para la mayoría de los autores decimonónicos hombres - y me atrevería a incluir también a muchas de las mujeres que entonces escribían a partir de la "autoridad textual" 15 definida por el discurso hegemónico androcéntrico - para Martí el erotismo femenino sólo podía ser visto conforme al ritual histórico de códigos, preferencias, sabiduría y tabúes, en pos de la regulación y el control social; esa "sexualidad socializada" de la que ha hablado Octavio Paz. Ésta constituía, desde luego, una instancia previa y plenamente canonizada por el complejo de determinaciones y características culturales inherentes al grupo sociocultural hispánico al que pertenecía Martí, y sería parte importante que pretendía refrendar en su proyecto frente a lo ajeno del universo anglosajón. Las variaciones que se introducen en su obra respecto a la estratificación genérica tradicional, que pueden ser percibidas de manera lenta, tímida, intermitente, a nuestro juicio sólo se impondrán de la mano de la problematización de la propia estratificación social en su sentido más amplio, que las tornó, al cabo, inevitables.

Así, el cuerpo femenino irá sigilosamente ganando terreno: variará su modo de representación en la medida en que la mujer se apropia de la

${ }^{13}$ Rafael Rojas, José Martí: la invención de Cuba, Madrid, Ed. Colibrí, 2000, p. 20.

${ }^{14}$ José Martí, “A su hermana Amelia”, en Obras completas,t. 20, p 287. Las cursivas son mías.

15 Jean Franco, "Si me permiten hablar: la lucha por el poder interpretativo", Casa de las Américas, núm. 171, 1988, pp. 88-96. 
escena social en los contextos donde Martí vive: cambia su papel, se visibiliza, vulnera la delimitación tradicional de los espacios sobre la base de la nueva organización social en marcha. Desde luego, es una variación que se introduce en su proyecto constructivo de nación, primero en lo puramente discursivo — su discurso del deseo, su deber ser-y sólo más tarde como reconocimiento fáctico. Ni siquiera al propio Martí le debió resultar fácil aceptar, en la práctica, la inminencia del abandono, "relativo", por parte de la mujer del ámbito privado, familiar, doméstico, y su inserción en el espacio público, hasta entonces casi exclusivamente masculino. Y esto tendría repercusión directa en el enriquecimiento de la sexualidad femenina en su discurso: en la progresiva desaparición del tabú en su placer, que se agregará a sus naturales comportamientos de apareamiento y de reproducción.

\section{III}

Percepción y pensamiento del cuerpo implicaron ya desde los textos iniciales martianos, laceración física y padecimiento existencial. Cuando a los dieciocho años concibe uno de los más conmovedores textos de nuestra literatura — su "Presidio político en Cuba" — inscribe por primera vez la presencia de su cuerpo y el de sus semejantes como angustia:

Dolor infinito debía ser el único nombre de estas páginas.

Dolor infinito, porque el dolor del presidio es el más rudo, el más devastador de los dolores, el que mata la inteligencia, y seca el alma, y deja en ella huellas que no se borrarán jamás. ${ }^{16}$

La marca corporal como cicatriz del alma: la sensación como mediadora entre cuerpo y alma — siendo el alma psique. ${ }^{17}$ Dirá más en

${ }^{16}$ José Martí, "Presidio político en Cuba", en Obras completas, t. 1, p. 45. Las cursivas son mías.

17 " $\mathrm{Al}$ alma pertenecen las facultades volitivas, intelectuales y sentimentales. No sensibles. La sensibilidad no es facultad del alma", especifica en sus "Cuadernos de apuntes", núm. 2, en Obras completas, p. 48. 
sus "Cuadernos de apuntes", a la altura de 1881, refiriéndose a otra prisión, célebre, cuando aún padece, como hasta el fin de sus días, las huellas físicas y psíquicas del presidio: “Aquella Bastilla, coronada de nubes negras, besada por aguas turbias, cercada de murallas roídas, hecha como para encarcelar — más que el cuerpo de los hombresel espíritu humano". ${ }^{18}$ Sin embargo, más tarde su concepción del cuerpo como "el barro" - la sustancia genésica, pero al mismo tiempo lo vilno se limitará a lo puramente material: de un modo bien peculiar le atribuirá, además, carácter subjetivo:

Lo que yo llamo cuerpo no es el cuerpo en sí, sino una especie de alma corpórea y levadura terrenal, con que los sentidos se mezclan en los sentimientos, yo llamo cuerpo a las mezquinas ideas, a las satisfacciones vanidosas, a todo lo que no siendo material no es sin embargo amor fraternal [...] El roce del alma con la tierra produce esa alma corporal. ${ }^{19}$

En este mismo sentido concluye, en 1894, reflexionando en torno al desarrollo espiritual y la dependencia que existe entre éste y el desarrollo corporal: "El objeto está fuera de mí; pero la inteligencia del objeto está en mí". ${ }^{20}$

Su experiencia de adolescente encarcelado había dado cuenta de una sexualidad precozmente contenida, represión consciente de los placeres de los sentidos, en pos de su consecución de una forma de existencia espiritual más elevada. ${ }^{21}$ Sus escrúpulos ante la arista carnal de la relación amorosa los encontramos por primera vez en carta enviada a su madre desde el presidio, cuando se declarara significativamente opuesto a la visita de prostitutas. Subrayaba entonces: "A Dios gracias el cuerpo de las mujeres se hizo para mí de piedra. - Su alma es lo in-

${ }^{18}$ Ibid., núm. 7, p. 220. Las cursivas son mías.

${ }^{19}$ Martí, "Otros fragmentos”, núm. 22, en op. cit., p. 322.

${ }^{20}$ Martí, "Cuadernos de apuntes”, núm. 18, en op. cit., p. 387.

${ }^{21}$ Llegará a expresarlo: "Yo no exijo las mortificaciones del cuerpo: yo voy levantando a cada muerto; y diciendo 'Amor; amor'." Martí, "Fragmentos”, núm. 138, en op. cit., p. 83 . 
mensamente grande, y si la tienen fea, bien pueden irse a brindar a otro lado sus hermosuras_-".22 Más allá de la natural e ingenua vergüenza juvenil con que es rechazado el placer corporal ante los ojos maternos - tal vez hasta con el simple propósito de aplacar la inquietud de doña Leonor al respecto- - el hecho de que en una breve misiva destaque, por sobre otras vivencias, tal asunto y manifieste tan secamente su censura, nos ha de hacer pensar en fuertes criterios predefinidos. En realidad denota una preocupación que no habrá de abandonarlo nunca. Aun en 1894, en un cuaderno de apuntes, la expresa como incertidumbre no resuelta:

¿Y cómo un padre inicia a su hijo decorosamente en el conocimiento de la vida sexual -o debe dejarse al azar este asunto de que depende tal vez la vida entera o hay tal ley en el hombre que ella sola le guía, o debe ser la guía del padre indirecta y no más? [...] Eso, y el sufragio son tal vez las únicas cosas que me han hecho dudar. ${ }^{23}$

Pero el cuerpo, entonces sólo pecado — manifestación de la caída del espíritu desde el ámbito divino y su encarcelamiento en el demoniaco mundo material: el pecado corruptor de la naturaleza humana, a la manera cristiana-, se convierte a un tiempo en misterio y constante tentación al calor de su primer destierro y su convivencia con los "placeres mundanos" - la tertulia, el café, el teatro- que se le ofrecen durante y a partir de su estancia en la, sin embargo, tan aparentemente pacata metrópoli. Allí "rompió su corola" la "poca flor" de su vida, ${ }^{24}$ no sólo ante el inmaculado amor despertado por Blanca de Montalvo sino al, a todas luces, carnal mantenido con "M" — "la Madrileña"— durante los cuatro años de exilio español. ${ }^{25}$ Muy rápido se duele de la corporeidad

${ }^{22}$ Martí, "A su madre”, en Obras completas, t. 1, p. 41. Las cursivas son mías.

${ }^{23}$ Martí, "Cuadernos de apuntes”, núm. 18, en op. cit., p. 415. Las cursivas son mías.

${ }^{24}$ Martí, "Versos sencillos”, poema VII, en Obras completas, t. 22, p. 83.

${ }^{25}$ Véanse las cartas de Blanca de Montalvo y de "M" dirigidas a Martí, quien se había marchado a México, en Luis García Pascual [comp.], Destinatario José Martí, La Habana, Casa Editora Abril, 1999, pp. 11, 12, 14, 15, 16 у 29. 
"impura" que se le impone: "Nosotros, mezcla de espíritu que anima y cuerpo que obedece, el espíritu hace cometer el delito, el espíritu es el único responsable del delito, el espíritu —obcecado o pervertido."26

En otras oportunidades me he referido con detenimiento a textos donde pueden registrarse elementos muy significativos respecto a la evolución de su pensamiento del cuerpo inscrito en discursos con vocación ancilar. ${ }^{27}$ Es el caso de la primera versión de Adúltera - comenzada a sus dieciocho años, en 1872 y finalizada en 1874: el tópico de la lucha entre el espíritu y la carne es abordado en las reflexiones de censura a la mujer, que ejecutan dos personajes positivos, desde luego, masculinos. Reveladoramente, la esposa infiel, que desencadena el conflicto, es nombrada Fleich: en alemán "carne". Con un parlamento inicial elocuente pronunciado por su esposo - Grossermann, es decir: el "hombre alto", el marido, y atiéndase a la posición de dominio pleno que el adjetivo le otorga dentro de la pareja - se enuncia de inmediato el punto de vista defendido por el autor:

Cuerpo y alma son ciertamente encarnizados contrarios. No es amor estúpido de cuerpo lo que brota de mí para María [a quien luego llamaría Fleich]:es que el ser humano no está completo en el hombre: es que la mujer lo completa: es que esta indomable vida de mi espíritu necesitaba para no caer vencida $[\ldots] . .^{28}$

En consecuencia, los retratos femeninos, que coloca en boca de sus personajes, se sustentarán más en la dimensión espiritual de la dicotomía. No sabremos nunca el aspecto físico de la referida hermana de Guttermann, el amigo, "hombre bueno". Incluso, de la belleza de la propia Fleich, sólo

${ }^{26}$ Martí, "Cuadernos de apuntes", núm. 1, en op. cit., p. 23.

27 Véase "Lucía Jerez como espacio de angustia decimonónica”, Anuario Centro de Estudios Martianos, núm. 23; "Eros y nación en el discurso narrativo modernista", Cauce, núm. 4, 2002; "Ocho notas en torno al cuerpo de/en José Martî”, Islas, núm. 136, 2003.

${ }^{28}$ José Martí, “Adúltera”, en Obras completas, t. 18, p. 132. Las cursivas son mías. 
sabremos a través de una referencia puesta en boca del amante, que resulta, por tanto, de signo negativo. Éste la esboza apenas cuando testifica la "impureza” de su propio enardecimiento en el reclamo: “...a mí que ciego con el esplendor de tu hermosura, a mí que tiemblo a tu lado de delirio y de pasión, ¡ámame con suavísimo cariño, con dulce e infinito amor!"

Sí sabremos, en cambio, con holgura de la castidad primigenia y de la posterior "debilidad" de ambas mujeres frente a la tentación del amor carnal censurado por el canon asumido, mediante las reiteradas reflexiones de los incólumes y honorables Grossermann y Guttermann. Opina el primero, por ejemplo: “¡Fue que la sensualidad, que es el infierno, venció a la castidad, que es Dios!" La preeminencia del erotismo espiritual frente al sensual — que reproduce la dicotomía de origen teológico espíritu-cuerpo en la dualidad equivalente hombre-mujer- justifica la posesión por parte del primero y la dependencia incondicional por parte de la segunda: acredita la propiedad absoluta por parte del más fuerte, el hombre, del alma, e implícitamente del cuerpo-objeto, de la mujer. Así lo expresa Grossermann a su esposa: "Para mí, para mí solo tu alma entera, tu vida de antes, tu vida de ahora, el menor de tus pensamientos, todas tus vidas._- ¿Verdad, luz mía, que todo es para mí?”

Contemporáneamente, en 1875, tenemos constancia, gracias a un texto publicado en las páginas de la Revista Universal de México, de cómo Martí, aunque acepta hipotéticamente la nueva inserción de la mujer moderna en el ámbito público, el caso de las escritoras, como veremos, recela respecto a su posible violación del espacio tradicionalmente masculino. Allí censura, y de paso estigmatiza, a Gertrudis Gómez de Avellaneda, quien actúa obviamente fuera del papel a ella asignado "La Avellaneda es atrevidamente grande", ${ }^{29}$ dice, y para hacerlo harto evidente la coloca frente a la "fuerza de pasión delicada y de ternura", al "pudor", a la timidez, que aprecia, en cambio, en la personalidad y la obra de Luisa Pérez de Zambrana: "Hay un hombre altivo, a las veces

${ }^{29}$ Martí, “Tres libros. Poetisas americanas”, en Obras completas, t. 8, p. 311. 
fiero, en la poesía de la Avellaneda: hay en todos los versos de Luisa un alma clara de mujer", ${ }^{30}$ afirma. Evidentemente, La Peregrina - y por razones extra literarias seguramente, en tanto mujer-sujeto, y sólo un repaso somero de su biografía permite evidenciar cuánto lo fue- no alcanza entonces la aprobación franca que otorga a la voz desespañolizada y la vocación intimista de la Zambrana, nacida en el ambiente familiar campesino y adscrita, modesta y devotamente, al papel "natural" que la viudez le había prescrito. No aprecia en nada el "ánimo potente y varonil" en una mujer, al menos a esa altura de su vida. Veamos la descripción física que compone:

Era su cuerpo alto y robusto, como su poesía ruda y enérgica; no tuvieron las ternuras miradas para sus ojos, llenos siempre de extraño fulgor y de dominio: era algo así como una nube amenazante. ${ }^{31}$

Un ejemplo tan elocuente como éste, entresacado de la obra del que fuera sin dudas uno de los pensadores occidentales más avanzados del siglo XIX, demuestra fehacientemente lo que se sabe: que el libre albedrío esgrimido por los iluministas, o sea la capacidad del individuo para elegir una línea de actuación o tomar una decisión sin ser limitado por predeterminaciones — morales, religiosas, legales — poco cambió en la práctica la subalternidad femenina en la mayoría de las sociedades; máxime en las nuestras, donde la Colonia había dejado su herencia de excesiva permisividad para el hombre y de mordaza y explotación para la mujer. Ello no negó la posibilidad de que algunas, precisamente como la Avellaneda, marcaran con su impronta la época, cultural y conductualmente, e inauguraran un paso para sus semejantes en el espacio público, "amenazando" la preeminencia masculina, tal cual en ese momento lo valora Martí. Tengamos en cuenta que estas operaciones femeninas de penetración aún vacilante en el ámbito de lo prohibido eran ejecutadas en momentos en que el pensamiento moderno, expresión de poder mascu-

${ }^{30}$ Ibid., pp. 310-311.

${ }^{31}$ Ibid., p. 311. Las cursivas son mías. 
lino, podría haber facilitado, y no lo hizo, un paso importantísimo en su historia, o al menos semejante al dado por el hombre: la transformación posible de objeto de acción a sujeto de ella, un proceso que, no obstante se había iniciado ya, incluso a contrapelo y dentro del propio discurso masculino, la obra de Martí es un buen ejemplo.

Lo cierto es que cuatro años después de estas reflexiones en torno a La Peregrina, en un libro de apuntes presumiblemente de 1879, correspondiendo a su segunda deportación a España, Martí incluye un texto en torno a la figura de Goya que, aunque se permite la recreación literaria de la voluptuosidad explícita en la figura de La maja vestida y el reconocimiento implícito de la existencia del placer femenino en el contexto de un hecho artístico que, en su conjunto, aprueba, supone todavía una censura a la posibilidad pecaminosa de que la mujer participe de la celebración de los sentidos.

Nunca negros ojos de mujer, ni encendida mejilla, ni morisca ceja, ni breve, afilada y roja boca, ni lánguida pereza, ni cuanto de bello y deleitoso el pecaminoso pensamiento del amor andaluz, sin nada que pretenda revelarlo exteriormente, ni lo afee, halló expresión más rica que en La Maja. No piensa en un hombre; sueña. ${ }^{32}$

Es evidente su intención de salvar a toda costa la imagen de la mujer impura que, muy a su pesar, lo fascina: significativamente asegura que la Maja sólo "sueña", es decir, "no piensa en un hombre" concreto, sensible, corpóreo. La corporeización erótica aparece, pues, aunque escamoteada por la dimensión estética: belleza y deleite comienzan, confusamente a andar unidos. La erotización femenina resulta admisible en el espacio artístico, aún no en la vida cotidiana. Lo reitera, por ejemplo, en "El desnudo en el salón", publicado en The Hour, al año siguiente, cuando coloca como condición de excelencia nada menos que la pulsión erótica que sea capaz de despertar el artista a través de la mujer-objeto.

${ }^{32}$ Martí, “Goya”, en Obras completas, t. 15, p. 131. Las cursivas son mías. 
Esas mujeres desnudas deben de poder tentar como la de Camille de Beaumont tienta a san Antonio; ellas deben de enardecer y matar de una mirada como La Maja de Goya, uno de los cuadros más maravillosos que jamás ha salido de manos humanas. ${ }^{33}$

La permisividad está claramente delineada: para el hombre y, aquí en específico, para el artista y para el espectador masculino. La mujer objetuada debe tentar, debe enardecer... puede ser admitida en tanto cumple su deber ser en el ámbito preciso y vedado que surge en torno al hecho artístico, creado por y para el hombre. En cambio, recordemos que en ese mismo 1880 aún le escribe a su hermana Amelia reduciéndole las cotas del amor apenas al "apegamiento inefable de un espíritu a otro". ${ }^{34}$

\section{IV}

En su segunda versión de Adúltera, lamentablemente inconclusa y de $1884,{ }^{35}$ las modificaciones reflejan, a mi juicio, el compromiso del autor con referentes socioculturales distintos. Martí tiene treinta y un años, se ha establecido en Estados Unidos, ha vivido ya las experiencias visceralmente enriquecedoras que le brindaran sus estancias en México, Guatemala y Venezuela, las penalidades de un hogar errante, de una

${ }^{33}$ Martí, "El desnudo en el salón”, en Obras completas, t. 19, p. 262. Las cursivas son mías.

${ }^{34}$ Martí, “A su hermana Amelia”, en Obras completas, t. 20, p 287. Las cursivas son mías.

${ }^{35}$ Existen dos hipótesis respecto al posible fechado de la segunda versión de este drama martiano: una sustenta que fue revisado entre febrero de 1877, tras realizar su lectura pública en La Habana, y marzo de 1879, cuando Martí protagonizara el debate sobre idealismo y realismo en el arte, con el que parece relacionarse a partir de un apunte que se lee al dorso y que se refiere a lo allí acontecido; otra hipótesis, defendida por Gonzalo de Quesada y Miranda en su prólogo a la primera edición, afirma que el grueso de las correcciones debió realizarlas en Nueva York, en 1884. Por la coincidencia de algunas de sus enmiendas con el espíritu que anima su novela Amistad funesta, publicada por entregas apenas al año siguiente, me inclino a considerarlas contemporáneas, dando la razón a Quesada. 
familia dividida, de su amor frustrado por Carmen Zayas-Bazán, evento que constituye, sin dudas, motivo de conflicto con su deber ser, en la medida en que se debilita el canon que ha tratado de asumir. Al revisar Adúltera, la aligera la densa severidad moral que lastra a la versión original, e incluso se empeña veladamente por encontrar, mediante complejización psicológica del personaje, justificación al adulterio femenino, al tiempo en que reivindica abiertamente su derecho al placer sexual. No ha permanecido para él oculta la tragedia cotidiana de muchas mujeres de la época, casadas inadecuadamente y sometidas a la agonía privada de un destino infeliz so pena de recibir el implacable repudio público.

El derecho femenino a la realización personal comienza a ganar terreno: primero, el amante de Fleich denuncia que su arrebato pasional es compartido, de igual modo, por ella — "Y cuánto gozo cuando palpitante de felicidad te precipitas en mis brazos y toma expresión de niña tu semblante; y en mí buscas refugio de placeres a tu embriaguez y tu alegría" - ${ }^{36} \mathrm{y}$, finalmente, aquella que antes sólo alcanzaba a lamentarse de su debilidad y su culpa, ahora escenifica un monólogo capaz de aducir razones elocuentes, aunque aún censurables, respecto a su conducta infiel:

Es verdad que Grossmann [el esposo] es bueno; pero Pesen [el amante] es mucho más bello que él: hay hilos de plata en la cabellera de mi Grossmann: los cabellos de Pesen son negros y brillantes.

No entiendo yo a mi marido cuando me habla, y entiendo tan bien las cosas que me dice el gallardo Pesen [...] yo hallo placer secreto cuando me estrechan los brazos de Pesen. ${ }^{37}$

Las incorpóreas mujeres de la primera versión han encarnado. Ahora se presenta, incluso, el retrato físico de la hermana impura. Aquí Freund, el "amigo", antes Guttermann, el "hombre bueno", se lamenta de su

${ }^{36}$ Martí, "Adúltera”, en Obras completas, t. 18, p. 227. Las cursivas son mías.

${ }^{37}$ Ibid., p. 225. Las cursivas son mías. 
"caída" no sólo rememorando las virtudes perdidas, como hiciera en el caso anterior, sino que describe su virginal belleza como expresión del alma, con una mirada ansiosa y añorante que más parece responder a la de un amante engañado. Cito:

Ella era blanca y rubia, el sol copió sus rayos de sus cabellos y los celajes de la tarde envidiaban las nubes de sus ojos; se vestía de blanco, y parecía una pálida visita de tierras ignoradas [...]. Andaba lentamente y semejaba nube detenida un instante sobre la superficie de la Tierra [...] quémase en el ara de un amor impuro, deja el ángel sus alas en ardiente hoguera; váseme en villanos brazos la que con estos míos honrados sostuve y alenté. ${ }^{38}$

El protagonismo del cuerpo femenino comienza a ser un hecho. Sólo un año después de la fecha probable para la revisión de Adúltera, Martí concibe su única novela: Amistad funesta, posteriormente retitulada Lucía Jerez. La posible fuente de inspiración para su trama novelística la hallamos en sus "Cuadernos de apuntes", con fecha contemporánea a la concepción de la novela. Martí cita Viaje de novios (1881), de Emilia Pardo Bazán, lo que nos lleva a suponer el posible germen de la Lucía martiana en la Lucía peninsular de la escritora gallega. La referencia que incluye en sus anotaciones apunta a nuestro tema: "Se desarrollaron paralelamente en Lucía el espíritu y el cuerpo, como dos compañeros que se dan el brazo para subir las cuestas y andar mal los caminos". 39 Martí asimila esa confluencia, pero, desde luego, como dicotomía, como perenne lucha de contrarios en el dibujo atormentado de la Jerez, cuyo mayor conflicto con su entorno, el explícito, al menos, es de orden, justamente, erótico.

Llegará el momento en que el Apóstol se cuestione la validez de esa misma dualidad esencial de la cual habíamos partido en nuestra indagación: “¿Por qué han de ser enemigos el alma y el cuerpo; lo que tiende a escaparse y lo que tiende a retener?", se cuestiona, ${ }^{40}$ y res-

\footnotetext{
38 Ibid., p. 208.

39 Martí, "Cuadernos de apuntes", núm. 12 en op. cit., p. 281.

${ }^{40}$ Martí, "Fragmentos”, núm. 310, en ibid., p. 221.
} 
ponde presumiblemente a la altura de 1894: "lo que hay que probar es que conforme se va desarrollando el cuerpo se va desarrollando el espíritu". 41

Sin embargo, aún la evolución del personaje de Lucía, el protagónico $\mathrm{y}$, sin dudas, el mejor estructurado, contradice, incluso, las reflexiones edificantes del narrador y la actuación de sus personajes positivos. Su discurso erótico, colocado en un primer plano bien convincente, se divorcia del canon propuesto y parece conectarse con los debates inherentes al yo más íntimo martiano — especialmente evidentes a lo largo de sus "Cuadernos de apuntes"- y a su propia praxis. La caída final, resultado de la "impureza" femenina, como la de la Fleich, de Adúltera, ha sido de algún modo anticipada a través de la incólume Ana — a todas luces portadora de valores arquetípicos que le interesa fijar-, quien proyectara un cuadro donde París aparece como "un monstruo con cabeza de mujer", devorando rosas; una escena que ha de conectarse con momentos de sus Versos libres, como "Amor de ciudad grande" o "Mi poesía".

No es posible dejar de percibir cómo uno de los elementos que subrayan la sexualidad atormentada de Lucía - motivo central, abiertamente portador de dudas y tribulaciones martianas - es su retrato físico, directamente emparentado con el antes citado de la enjuiciada Avellaneda. Lucía es mujer más alta "de lo que sentaba a sus años $y$ sexo", ${ }^{42}$ en quien resaltaban "sus ojos llameantes, como dos amenazas". ${ }^{43}$ Ella "amaba lo extraordinario y poderoso": ${ }^{44}$ es un dibujo de rasgos voluntariamente envilecidos, dirigido a prevenir y aleccionar al público femenino, lo cual no impide que la muchacha posea un tipo especial y cautivante de belleza: la belleza de lo prohibido.

${ }^{41}$ Martí, “Cuadernos de apuntes”, núm. 18, en ibid., p. 387.

42 José Martí, Lucía Jerez, ed. crítica y pról. de Mauricio Núñez, Ciudad de La Habana, Ed. Centro de Estudios Martianos, 2000, pp. 65-66. Las cursivas son mías.

${ }^{43}$ Ibid., p. 66. Las cursivas son mías.

${ }^{44}$ Ibid., p. 60. 
Se trata de la robusta mujer masculina que, según María Poumier, ${ }^{45}$ seduce a Martí muy a pesar suyo, con la cual convive a diario en las calles de Nueva York, independiente y activa, pero, también, en otro sentido, la femme fatale francesa, de atractivo erótico indefinible, venida de la poesía de Baudelaire y los decadentes: portadora de contradicciones éticas insalvables y sentimientos difusos de angustia que se reflejan en una corporeidad exageradamente exaltada, capaz de manifestar en forma de síntomas físicos sus conflictos emocionales reprimidos. La briosa, desequilibrada y pasional Lucía resulta símbolo de los "desquiciados" nuevos tiempos a los que con reiteración alude, pero, a un tiempo, su conflictividad reafirma, en parte, el ideal femenino romántico según el cual la mujer era por excelencia proclive a los estados perturbados, por su naturaleza menos racional que la del hombre.

Así, el cismático ser de Lucía Jerez por momentos impugna abiertamente el deber ser femenino que el autor pretende proponer:

Lucía, que padecía de amarle, y le amaba irrevocablemente, y era bella a los ojos de Juan Jerez, puesto que era pura [deber ser], sintió una noche [...] que Juan Jerez, lisonjeado por aquella magnífica tristeza, daba un beso, largo y blando, en su otra mano. Toda la habitación le pareció a Lucía llena de flores; del cristal del espejo creyó ver salir llamas; cerró los ojos, como se cierran siempre en todo instante de dicha suprema [...] y para que no cayese en tierra, los mismos brazos de Juan tuvieron delicadamente que servir de apoyo a aquel cuerpo envuelto en tules blancos, de que en aquella hora de nacimiento parecía brotar luz. ${ }^{46}$

Martí despierta en Lucía -y lo justifica conceptualmente, mucho más que en el caso del adulterio de Fleich — una acusada conciencia perceptiva del mundo, activada a partir del contacto con el cuerpo amado, que no parece corresponder al papel por él previsto para la mujer a

${ }^{45}$ María Poumier, “Armas, Casal, Martí y el sexo”, Vivarium, núm. 12, Ciudad de La Habana, Departamento de Medios de Comunicación Social, Arzobispado de La Habana, 1995.

${ }^{46}$ Martí, Lucía Jerez, en op. cit., p. 61. Las cursivas son mías. 
esa altura, obsérvese la connotación infernal que tienen las llamas que Lucía cree ver salir del espejo, que sugieren la perversión femenina a pesar de su pureza aparente.

No obstante semejante vulneración del canon martiano, aún el cuerpo se materializa sólo a través de veladuras, la atracción mayor la ejerce lo apenas atisbado. De cierto, su erotismo radica más en la inhibición que en la exaltación de los impulsos del deseo, de la libido, del placer: lo importante es aquí la exacerbación de la pulsión y el ritual, no la realización misma. Como el desnudamiento sugerido de la Maja vestida, recordemos aquel "vaporoso claror" que la rodea, ${ }^{47}$ es más inquietante y transgresor que la exposición directa del cuerpo de su gemela desnuda, así las mujeres jóvenes en Lucía Jerez dejan entrever su cuerpo como signo de la nueva visibilidad que tímidamente comienzan a asumir, danzantes y desembarazadas, sugeridas por las ligeras telas, en el salón, en el espacio público.

La recepción por parte de Martí en su novela del conflictivo silenciamiento forzado de la mujer, condicionaba necesariamente estados de reflexión cuestionadora y terminaba por abocarlo a una redefinición más audaz de su papel en la sociedad. En el caso de uno de sus personajes más controlados, Ana, la mujer aún responderá manifiestamente a un deber ser que, aunque le asegura un ámbito de participación social —el de un quehacer artístico y su afán por ser ilustrada, que le asegura independencia y la aleja del peligro de ser simple objeto de posesión masculina — no le impide conservar sus tradicionales virtudes femeninas: bondad, paciencia, tolerancia, vocación de sacrificio, encargadas de subrayar su espiritualidad. Lucía, sin embargo, mujer masculina al fin, amenazante, acusa una carnalidad extrema que se exacerba a partir de su limitación crónica de realización personal, especialmente, en el ámbito privado de lo sexual. Y ya se sabe en el caso específico del eros, que la libido crece con la represión y ha de buscar de algún modo su salida. Es una

${ }^{47}$ Martí, “Goya”, en op. cit., p. 134. Las cursivas son mías. 
mujer "al borde de un ataque de nervios", cuya actitud pugna ya violentamente por una inclusividad que - por no responder al canon previsto- - le es, de plano, negada.

La mujer en Lucía... intenta dejar de ser objeto, de una u otra forma, pero, además, como sujeto operante comienza a adquirir una cierta conciencia respecto a la necesidad de un deber ser que le permita proyectar una conducta adecuada a sus intereses.

\section{V}

En ciertos pasajes de la literatura de viaje martiana ocurre un registro mucho más abierto del cuerpo femenino, condicionado por el hecho obvio de que, generalmente, no son textos concebidos para ser publicados y porque esas "mujeres naturales" que lo ocupan —indias, negras, mestizas, ajenas a la cultura urbana poscolonial (o colonial, en el caso cubano) - se ubican fuera de los límites severos marcados por las cotas eróticas martianas: son habitantes de lugares intrincados o distantes de las ciudades, y participantes de patrones más flexibles de conducta sexual, relativos a modelos genéricos bien distintos. Ello libera al discurso masculino del pesado fardo de la conciencia del pecado bíblico y de las prescripciones en cuanto al deber ser femenino que ha venido estableciendo.

En el contexto de sus viajes, Martí siempre denota una experiencia emocional intensa, capaz de acercar la exploración literaria del ser humano a un punto de vista más rousseauniano, en especial respecto a la contradicción entre los valores morales y sensuales. La mirada testigo foránea — que describe una realidad ajena - se permite solazarse en detalles anatómicos femeninos enmarcados en descripciones que se tornan, por momentos, casi lúbricas, aunque parcialmente desvirtuadas por una atmósfera costumbrista. Desde sus apuntes de viaje, las supuestas deidades provocadoras — las clásicas Ceres y Pomonas-y las inspiradas sibilas ejercen sus desnudeces en medio de la feracidad telúrica americana, conminando al autor a desplegar ese "algo de epicúreo" que hay en "el sensual y movible ser humano". "El paganismo se rejuvenece”, había ya reconocido desde 1875, en la Revista Universal de Méxi- 
co: "Tienen los sentidos ahora el señorío exclusivo del teatro, y es meta y punto feliz de la actual Literatura, la descripción voluptuosa y amena de los fenómenos psicológicos-sensuales". ${ }^{48}$

Más tarde, de la mano de una mayor y variada experiencia, vendría su identificación con la peculiar naturaleza de los pueblos americanos; llegaría poco a poco a su comprensión desprejuiciada y tolerante de lo diverso, de lo distinto, de lo hasta contradictorio, en especial respecto a los papeles genéricos, que constantemente va revisando contra la vida. Así, por ejemplo, el caso de Lola, la mujer del arriero, que, atónito, describe física y psicológicamente en su "Diario de Izabal a Zacapa":

Su perfil es correcto, menuda la nariz, breve la boca, bien hecha la frente, aguda la barba [...] Anda a trancos, bebe agua en todos los ríos, come totopoxte sin cesar, ayuda a cargar y descargar a su marido. ${ }^{49}$

Lola acarrea y amarra; y sabe encinchar una bestia con una crueldad que disgusta y asombra. ${ }^{50}$

[...] el seno ipobre pudor! salta a los ojos con una abominable transparencia, porque apenas lo cubre la camisa de los días de fiesta, de finísima indiana, leve como el encaje y como el tul.—Y Aniceto la ama: esa es su Lola. $^{51}$

Nuestra hipótesis parece confirmarse al acercarnos a aquellos momentos donde se refiere a las muchachas citadinas - correspondientes a un entorno con el cual sí se identifica su proyecto nacional— de las cuales apenas deja ver "la mano ociosa" en las páginas de "La América Central":

[...] de andar perezoso, de miradas castas, vestidas como las mujeres del pueblo con el pelo en trenzas sobre el mantón, que ellas llaman pañolón; la

${ }^{48}$ Martí, "Escenas mexicanas", en Obras completas, t. 6, p. 285.

${ }^{49}$ José Martí, Obras completas, edición crítica, La Habana, Centro de Estudios Martianos, 2001, t. 5, p. 54.

${ }^{50}$ Ibid., p. 58.

${ }^{51}$ Ibid., pp. 45-46. 
mano ociosa contando a los flecos flotantes del mantón los goces infantiles o las primeras penas de su dueña". ${ }^{52}$

De camino a la campaña libertadora se percibe aún el tratamiento desprejuiciado de la corporeidad en el caso de las dominicanas y haitianas en general, pero sin hacer mayor distinción entre "naturales" y poblanas. En la primera parte de sus Diarios de campaña - justo durante el periplo entre Santo Domingo y Gran Inagua $-{ }^{53}$ los retratos de mujer aparecen particularmente signados por una carnalidad extrema de la cual el autor, ahora protagonista de los hechos narrados, con franqueza participa. ${ }^{54} \mathrm{El}$ viajero se detiene fascinado ante los encantos de la negra de Haití "una mocetona: de andar cazador, con la bata morada de cola, los pechos breves y altos", 55 de "la moza que pasa, desgoznada la cintura, poco al seno el talle", ${ }^{56}$ o aquella que viene "rechoncha y picante [con] los diez y seis años del busto saliéndosele del talle rojo". ${ }^{57}$ Pero, naturalmente, son otros los presupuestos vivenciales que lo asisten a esa altura.

Su pensamiento respecto al papel social previsto para la mujer en su proyecto nacional ya había variado sensiblemente, de lo cual habían sido termómetro fiel las páginas del periódico Patria. Para este momento, el traspaso de los límites de su época en la representación del cuerpo femenino —como reflejo, pues, de cualidades y actitudes no corporales como el acceso femenino a empleos antes restringidos al hombre, o su participación directa en la empresa revolucionaria que él anima- se

52 Martí, "La América Central”, en Obras completas, t. 19, p. 82.

${ }^{53}$ Sostengo la idea de que sus dos últimos cuadernos de viaje forman un mismo corpus literario. Véase José Martí, Diarios de campaña, ed. crit. Mayra Beatriz Martínez y Froilán Escobar, La Habana, Casa Editora Abril, 1996.

${ }^{54}$ En torno al tratamiento del eros a su paso por Santo Domingo y Haití, véase el interesante estudio de José Massip, "Contingencias eróticas por los caminos de Montecristi a Cabo Haitiano", en Martí ante sus diarios de guerra, La Habana, Ediciones UnIón, 2002, pp. 9-39.

${ }_{55}$ Martí, Diarios de campaña, p. 102.

${ }^{56}$ Ibid., p. 26.

${ }^{57}$ Ibid., p. 44. 
encarga de expresar el nuevo posicionamiento de las fronteras entre el espacio público y privado como consecuencia de las marcas que propone para el género y el papel específico que le asigna dentro de su proyecto moderno de nación. Las mujeres de Patria, sin abandonar, desde luego, hogares y familias, aspecto que bien se encarga, de un modo u otro, de siempre señalar, son destacadas en sus notas informativas y artículos por su "apoyo" eficiente a sus hijos y esposos comprometidos con la campaña en preparación, aunque, de igual modo y definitivamente, por la asunción de una civilidad activa que se atisba de modo tangencial en sus reflexiones:

[...] ni puede Patria dejar de advertir que las campañas de los pueblos sólo son débiles, cuando en ellas no se alista al corazón de la mujer; pero cuando la mujer se estremece y ayuda, cuando la mujer tímida y quieta en su natural, anima y aplaude, cuando la mujer culta y virtuosa unge la obra con la miel de su cariño-la obra es invencible..$^{58}$

Pero esta mujer que para el Martí de 1892 "anima", "aplaude" y "unge" — "ayuda" - , no es ya una figuración del deber ser propuesto por quien escribe, sino un sujeto que ocupa un lugar que, piadosa pero a la vez levantada, ${ }^{59}$ alma afable que hermosea ${ }^{60}$ pero desde una inteligencia viva, ${ }^{61}$ en la práctica, se ha ido ganando. Más tarde la fundación de los clubes revolucionarios en el seno de la inmigración de Estados Unidos y las Antillas, obviamente, la coloca más allá del auxilio a sus compañeros: es muestra del reclamo de un lugar semejante al del hombre. Si la sección "En Casa" es un registro de la presencia de aquellas flores que "alegran el corazón", ${ }^{62}$ espacio habitual de mención a las

\footnotetext{
${ }^{58}$ Martí, Obras completas, 2001, t. 5, pp. 16-17. Las cursivas son mías.

${ }^{59}$ Martí, "En Casa", en Obras completas, 2001, t. 5, p. 355.

${ }^{60}$ Loc. cit.

61 Ibid., p. 362.

${ }^{62}$ Ibid., p. 370.
} 
"criaturas más delicadas y sinceras, más mansas y piadosas", ${ }^{63}$ de homenaje a la matrona discreta "que, en plena juventud y riqueza, les sacrificó la vida" 64 a sus hijos, no puede dejar de reconocer en "Los cubanos de Filadelfia", de 1893, que

[...] no hubo para el Delegado premio mayor a los trabajos del día, que la reunión en la casa bullente, donde, para las funciones sociales de nuestro ideal, y para el tesón y fe en que la mujer nos aventaja, quedó fundado el Club de nuestras mujeres. ${ }^{65}$

Sin embargo, entre diciembre de 1893 y abril de 1894, Martí concibe tres textos significativos donde suscribirá abiertamente el arquetipo de las "vírgenes patronas", abordado con suma lucidez por Susana Montero en La cara oculta de la identidad nacional. ${ }^{66}$ Tal y como ésta apunta, se trata de "figuras tutelares" en las cuales "se concretaron a nivel del imaginario social las principales utopías liberales románticas", ${ }^{67}$ y donde las mujeres reproducen "la figura inmaculada, heroica y estática de la virgen" y la "relación de la figura mariana con la acción redentora/ liberadora de Jesucristo". ${ }^{68}$ Son esos representativos textos martianos "Mariana Maceo", "La madre de los Maceo" y "La mujer santa", que sería indispensable comentarlos ampliamente en alguna otra ocasión, porque tributan de forma paradigmática la permanencia de las vírgenes patronas en nuestro identitario nacional: estos escritos, y otros semejantes, fijan a través de la mención de figuras suficientemente reputadas, como puede ser Mariana Grajales, el típico patrón martiano de sujeto femenino, de heroica subalternidad.

${ }^{63}$ Ibid., p. 450.

${ }^{64}$ Ibid., p. 458.

${ }^{65}$ Martí, Obras completas, 2001, t. 5, p. 18.

${ }^{66}$ Susana Montero, La cara oculta de la identidad nacional, Santiago de Cuba, Editorial Oriente, 2003.

${ }^{67}$ Ibid., p. 99.

${ }^{68}$ Loc. cit. 
Apenas un mes después, en "Tres madres", añadirá, en cambio, elementos que contribuyen a acercar su ideal femenino a la realidad, al menos a la citadina; particularmente a la más concreta del exilio: la "lucha ardua" de la mujer cubana, huérfana o viuda, "por el trabajo independiente" ${ }^{69}$ En este caso, como en otros semejantes, el ejercicio laboral y político de la mujer vivenciado en el día a día de la comunidad neoyorquina, y el conocido durante sus recorridos organizativos de la contienda, añaden elementos bien paradójicos respecto al deber ser inicialmente planteado.

No es extraño, pues, que si en 1889, en La Edad de Oro, había dicho al niño — varón — que se "ha de trabajar, de andar, de estudiar, de ser fuerte" porque nace "para caballero" y ha de proteger a la niña, que "nace para madre", ${ }^{70}$ es decir, para reproductora en el espacio privado, seis años después llegue a recomendar justo lo mismo a "sus niñas", las Mantilla, en sus últimas cartas. Pregunta a María el 9 de abril, desde Cabo Haitiano:

¿Se prepara a la vida, al trabajo virtuoso e independiente de la vida, para ser igual o superior a los que vengan luego, cuando sea mujer, a hablarle de amores $[\ldots]$ ?.... ¿Piensa en el trabajo, libre y virtuoso, [...] para no tener que vender la libertad de su corazón y su hermosura por la mesa y por el vestido? Eso es lo que las mujeres esclavas,- -esclavas por su ignorancia y su incapacidad de valerse - llaman en el mundo "amor"? ?11

Las conmina a asumir las nuevas funciones que les impone el devenir histórico en el espacio público sin necesidad de la protección de un esposo impuesto, o incluso de la paternalista compañía afectuosa de un padre o un hermano. Así, a escasos días de su muerte, no delata incomodidad sino más bien complacencia ante el hecho de que la mujer consiga ejercer su libre albedrío, ser independiente y no sólo igual, sino

${ }^{69}$ Martí, Obras completas, 2001, t. 5, p. 28.

${ }^{70}$ Martí, "La Edad de Oro", en Obras completas, 1975, t. 18, p. 301.

${ }^{71}$ Martí, Diarios de campaña, p. 365. Las cursivas son mías. 
incluso superior al hombre, lo cual a todas luces torna admisible, a la postre, la merecida femineidad de la Avellaneda, de Fleich, de Lucía, de Lola y la de tantas mujeres que en su obra habían hasta entonces agonizado sobre el espinoso límite entre el espíritu y la carne.

Eso ha escrito desde Cabo Haitiano a María y Carmen Mantilla, que se preparan a hacer sus vidas en el ámbito neoyorquino. Sin embargo, al llegar a tierras cubanas, percibimos en las anotaciones de su diario un sensible retorno al predominio de las figuras marianas, en ajuste preciso al contexto cultural campesino que sirve de asiento a la guerra. Ya no es "el viajero" el que relata: ha llegado a su plena naturaleza entre sus iguales $^{72}$ y el compromiso con este contexto al que pertenece y debe responder ha de ser, desde luego, absoluto. En concordancia, la espiritualidad recobra su preeminencia y enmascara, por un lado, el ser sibarítico martiano, y, por otro, el deber ser que a esa altura ya entrevé para la mujer en la sociedad moderna americana, al cual, en última instancia, parece aspirar.

Apenas podemos descubrir la presencia de algunas jóvenes, quienes, por diversas razones, manifiestan una dinámica más activa en sus relaciones con los hombres ajenos, no hijos, ni padres, ni esposos, ni hermanos. Son aquellas, de igual modo, las que pudieran haberlo cautivado y aparecen, en cambio, ligerísimamente dibujadas: "la mujer india cobriza de ojos ardientes"; ${ }^{73}$ la hija de Caridad Pérez y Piñó de dieciséis años, que "se puso zapatos y túnico nuevo"74 para recibirlos; la muchacha que "De seno abierto y chancleta viene" a ofrecer - iofrecerse?- aguardiente verde, de yerbas", a la mesa del almuerzo opulento en La Mejorana.

Recordemos que no es ya sólo el autor sino el protagonista de su propio relato el que escribe: el hombre público. A la postre, ha de ceder

72 Véase la carta que envía a Carmen Miyares desde Baracoa el 16 de abril de 1895. Martí, Diarios de campaña, p. 368.

${ }^{73}$ Ibid., p. 250.

${ }^{74}$ Ibid., p. 252. 
el paso a los arquetípicos retratos de las matronas que, tras la línea de combate, han de respaldar la contienda: Domitila "ágil y buena", quien "salta al monte, y trae el pañuelo lleno de tomates, cilantro y orégano"; Caridad Pérez y Piñó, la mambisa que "seria, en sus chancletas, cuenta, una mano a la cintura y por el aire la otra, su historia de la guerra grande": la muerte del marido, el deambular con sus hijos por el monte, sus saberes de la medicina y la culinaria tradicional...; ${ }^{75}$ Emilia Sánchez Collé, esposa de José Rosalío Pacheco —_"su andaluza", y advirtamos el posesivo- ${ }^{76}$ que no quiere salirse de la guerra, sino quedarse "donde esté Rosalío", 77 "con su sonrisa dolorosa" y mientras "alrededor se le cuelgan los hijos". ${ }^{78} \mathrm{O}$ de probas muchachas como Panchita Venero, por quien El Generalísimo Máximo Gómez "sentía viva amistad que la opinión llamaba amores", ${ }^{79}$ y que prefirió morir antes de traicionar y ceder a los requerimientos carnales de un jefe de guerrilla español.

Significativamente, no deja de recoger la voz de Rosa Moreno, la campesina viuda, única que invoca desde la última página del diario el derecho de la mujer a vivir su completa civilidad — como una combatiente más - al tiempo que manda a la guerra a su único hijo: "allá murió tu padre: ya yo no puedo ir: tú ve". ${ }^{80}$ Ya no puede, pero, sin dudas, podría. El afán dialógico del discurso martiano, capaz de hacer espacio a la heterogeneidad, brinda un marco propicio para reflejar este singularísimo ejemplo — aunque como excepción — sin que ello implicara la desestabilización del canon tradicional que su diario final reivindica.

Porque el espacio de la insurrección, el de la mambisada, ante la mirada del dirigente de la contienda que lo describe, se construye como un universo eminentemente androcéntrico. Martí testimoniante fiel de ese entorno cultural en que no sólo actúa sino del que participa y que

${ }^{75}$ Ibid., p. 250.

${ }^{76}$ Ibid., p. 336.

${ }^{77}$ Ibid., p. 333.

${ }^{78}$ Ibid., p. 334.

${ }^{79}$ Ibid., p. 318.

${ }^{80}$ Ibid., p. 346. 
desea reconocer, al fin, como suyo, se adscribe a los patrones culturales que le son inherentes.

Las reiteradas referencias a la corporeidad del hombre, en contraposición a las poco frecuentes alusiones a la femenina, lo reintegran, sin fisura, como dueño del espacio público. Son numerosísimas las descripciones donde los hombres de la guerra expresan su carácter, sus cualidades morales y sentimientos a partir del registro de sus características físicas:

[...] el abrazo de Luis, con sus ojos sonrientes, como su dentadura, su barba cana al rape, y su rostro, espacioso y sereno, de limpio color negro. ${ }^{81}$

[...] Ramón, el hijo de Eufemio, con su suave tez achocolatada, como bronce carmíneo, y su fina y perfecta cabeza, y su ágil cuerpo púber, Magdaleno, de magnífico molde, pie firme, caña enjuta, pantorrilla volada, muslo largo, tórax pleno, brazos graciosos, en el cuello delgado la cabeza pura, de bozo y barba crespa [...]. ${ }^{82}$

Es Casiano Leyva [...] entre los tumbadores el primero, con su hacha potente: y al descubrirse le veo el noble rostro, frente alta y fugitiva, combada al medio, ojos mansos y firmes, de gran cuenca; entre pómulos anchos; nariz pura; y hacia la barba aguda la pera canosa: es heroica la caja de cuerpo, subida en las piernas delgadas: una bala, en la pierna[...]. ${ }^{83}$

Ninguna de las descripciones femeninas de su último diario puede compararse a éstas. Son los rasgos con que se trazan los arquetipos que propone: para ellos las virtudes del cuerpo —un cuerpo que habla por sí mismo-; para ellas las virtudes del alma, las que justo han de amordazar el cuerpo.

En tal entramado narrativo, las mujeres constituyen sólo un agregado feliz, trasegando a los márgenes, dibujadas con evidente complacencia, pero marginadas al fin, componiendo el decorado que sirve de esce-

${ }^{81}$ Ibid., p. 256.

${ }^{82}$ Ibid., p. 260.

${ }^{83}$ Ibid., pp. 339-340. 
nario a la contienda. Mientras nos concentramos cada vez más en los acontecimientos, las escuchamos apenas, las vemos fugazmente, pero podemos adivinarlas siempre como tras una veladura respetuosa, tras una frontera amable que las protege, siempre ocupadas en sus labores: la Niña manda comida a la tropa, la mujer india y la mujer de Rosalío pilan café, Domitila va al monte a buscarles de provisiones, Caridad les trae café y cilantro de Castilla, la mujer de Pedro Pérez les manda la primera bandera... Resultan apreciadas, precisamente, por eso: en tanto sujetos operantes, sí, pero condicionados por el ámbito familiar, por el cual ha de pasar, exclusivamente, su incipiente civilidad. Es así la práctica patriótica asignada, su definido papel de respaldo al orden previsto, patriarcal en sus raíces, fundamentado en sus virtudes espirituales como madres y esposas, el desprendimiento, la piedad, la laboriosidad, la fidelidad, la castidad y la abnegación sin límites, que las retornan a su ancestral mutismo. En tierra cubana, la mujer es silenciada; vuelve a ser, necesariamente, aquella "[...] alma que late en un cuerpo que no puede revelar el alma". ${ }^{84}$

${ }^{84}$ Martí, "Cuadernos de apuntes", núm. 3, en Obras completas, 1975, p. 106. 